\title{
Sustainable Development and Exploitation of Semi-mountainous Area in Greece
}

\author{
Vasileios C. Drosos, Sarantis Angelos G. Liampas, and Christos C. Stamatiou
}

\begin{abstract}
Sustainable development of semi-mountainous regions supports an increase in economic investments in order to profit the residents of region, without however having drastic negative influences on the natural environment. Green Infrastructure (GI) can be broadly defined as a strategically planned network of high quality natural and semi-natural areas with other environmental features, which is designed and managed to deliver a wide range of ecosystem services and protect biodiversity. The objective of this study is the specification of strategic directions for an integrated development of semi-mountainous areas through global measures in relation to zoning policies and also proposals regarding specialized production activities, according to a proper typology that characterizes the differentiation of regional problems, needs, and perspectives. The sustainable development of the semi-mountainous areas of Greece targets regional and social cohesion in the framework of especial strategic targets.
\end{abstract}

Index Terms - Zoning, sustainable development, exploitation.

\section{INTRODUCTION}

It makes one wonder whether the belief of showing indifference towards environmental issues and overexploitation of natural resources is a new trend that used to exist in the past as well. Recent researches of prehistoric period have shown that ecological disasters have been an integral part of main evolutionary course. Floods and droughts were anomalies that occurred in the past as well. But their frequency, range and size of these natural disasters have increased dramatically thus led to economic disasters as well. Adding thoughtless industrial growth without any planning at all for the last decades have given a final shot to a natural environment, already burdened by an industrial revolution which started two centuries ago. However, the quality and quantity of human intervention in the second half of the 20th century have been decisive for a permanent wide range disjunction in the environment, but also creating the idea of "environmental sustainable development".

Sustainability is today one of the most widely used words in the scientific field as a whole and in the environmental sciences in particular, but the analysis of the evolution of such a concept is a difficult exercise. This is because the records of the systematic use of such an expression, whose reference in the current vocabulary and political discourse is nowadays so popular, are scattered around. Until the late 1970s, the "word"

Manuscript received May 9, 2015; revised July 31, 2015.

The authors are with the Department of Forestry and Management of the Environment and Natural Resources, Democritus University of Thrace, Orestiada, $68200 \quad$ Greece (e-mail: vdrosos@fmenr.duth.gr, angel40das@yahoo.gr, stamatioy@gmail.com). sustainability was only occasionally employed, in most cases to refer to ways through which forest resources should be used. It has, in other words, strong connections with the forestry sector from where, some believe, it originated.

Other than that, the expression "sustainability" has been traditionally used as synonymous with words such as "long-term", "durable", "sound" or "systematic", among others. Indeed, out of the context of the English language, sustainable development is very often referred to as "durable development" in French, while word-by-word translations are found in the German (nachhaltige Entwicklung), Spanish (desarrollo sostenible) and Portuguese (desenvolvimento sustentaÂvel) languages.

The man acting as an independent and dynamic human being has begun a hard and endless fight of competition and predominance in the nature and its forces. That resulted to destructions of preexisted flora, fauna and natural ecosystems. Recording of anthropogenic impacts to the natural environment forms a fundamental protection element [1]. Greek forests are an invaluable source of products and services. However, due to severe exploitation and fires they have been degraded seriously. To improve their condition, sound management procedures should be applied by forest managers. To do so, accurate and up to date inventory data are required.

The development of semi-mountainous and mountainous forest areas is the main objective of the forest policy implemented today in our country. However, development entails human intervention in natural environment, leading to its alteration and often its degradation.

One of the most important human interventions in a forest ecosystem is the construction of a network of transport facilities (forest roads, trail, skidding roads etc.), which contributes in the transportation of forest products, tourism development and forest protection [2], [3].

However, apart from the said positive effects, opening up works burdens environment and damages the landscape. Sometimes said damages may be restored but in most cases this is impossible. These effects cannot be evaluated based on economic features in the framework of the known decision-making methods such as cost-benefit analysis and other mathematical methods.

The term "compatibility with the environment" means to define, describe and assess the effects of a construction work on the environment and to take measures for its protection. Thus, the primary concern of a forest engineer should be the compatibility of such opening up works with the environment. For this reason, the assessment criteria for forest technical works are used in order to examine and evaluate the impact of works on natural environment, as well as to choose the best 
(compatible) environmental solution among various alternatives before the construction of roads [4].

Rapid development in the field of P/C and GIS software now enables the examination and analysis of the said criteria in an objective and cost-effective manner [5].

A Geographical Information System (GIS) is an organized collection of computer hardware, software, data and personnel designed to efficiently capture, store, update, manipulate, analyse and display all forms of geographically referenced information [6]. The GIS data model includes spatial and attribute data and therefore a GIS database design must accommodate doth kinds of data, requiring different kinds of data structure. The GIS database design usually relates to one specific project, for which only one database structure is suited, but since a GIS can handle more than one project and database, more database structures can be designed for the different user's needs for different GIS projects [7].

The data of GIS emanate from different sources, as digitalisation of charts, tables of inventories, topographic work, photogrammetric performance, typing of data and digital products that because their different characteristics cannot combine themselves simply from each other. Two primary categories of geographic data are recognized: spatial and thematic, each affecting the design of the database. Spatial data describe the location of geographic features.

Thematic data (attribute or tabular) describe characteristics of geographic features. Spatial information is presented as vector data in the form of points, lines and areas (polygons), or as grid data (raster) in the form of uniform, systematically organized cells. Attribute data consist of qualitative or quantitative data, according to their characteristics. A major strength of a GIS is that it can accept and merge diverse data into a single database, giving the user a flexible and powerful set of data which to work.

In order to bring the real world into a GIS, we must abstract the real world phenomena to store them digitally represent them with graphic symbols on maps and perform geographic analysis. Converting the real world into a data model facilitates the study of a selected area of application by reducing the number of complexities considered.

Therefore, before the information is entered in a database, we must first select the appropriate carriers of information and determine their relationships, according to specific criteria for each project.

The continually evolving computer technology and significant advances in the software now allows the creation of geographical information system with high potential for output and presentation of information, application of complex models to data analysis, and the creation of simulation modelling. The main problem in implementing such systems is therefore the creation of appropriate databases and the frequent renewal.

The objective of this study is the specification of strategic directions for an integrated development of semi-mountainous areas through global measures in relation to zoning policies and also proposals regarding specialized production activities, according to a proper typology that characterizes the differentiation of regional problems, needs, and perspectives.

\section{MATERIALS AND METHODS}

Finally, there is the crucial question, which the structure of zoning will be. Since zoning of mountainous areas should be occupied, in the framework of an organic and flexible plan for land use, with ensuring the cultivable land, the hydrologic network, forests and forest lands, traditional-cultural heritage and area development in the framework of preserving the compatibility with the environment. According to the above, zoning development of mountainous areas should be consistent of [8], [9]:

1) Geographical position, boundaries and extend of the study area.

2) Description of the existing conditions of the natural or ecological environment.

- Topographical, edaphically, geologic and petrographic elements.

- Flora - fauna - biotopes - climatic elements.

- Raw material, sanative sources and natural energy resources.

3) Description of the existing conditions of human environment.

- Ownership.

- Population evolvement.

- Economic status.

- Current activities.

4) Description of the existing situation of the artificial environment.

- Service networks, buildings etc.

- Transportation and opening up.

5) Description of the existing condition of the cultural environment.

- Historical - traditional - cultural elements.

6) Potentialities and perspectives for development - targets.

- Pursued developmental type, activities that have to be developed and developmental target.

- Infrastructure works.

- Activities and interventions required for promoting the forest area to a natural, cultural and tourist pole of the country.

7) Works suggestions - land uses.

8) Techno-financial elements.

9) Environmental compatibility control with the environment.

The environmental consequences of the investment plan are evaluated and both activities and interventions necessary for natural environment protection are recommended. The effect of the project is done:

- On the natural environment.

- On the human environment.

- On the artificial environment.

- On the cultural environment.

- On the institutional environment.

Developmental works in an area use (negative consequence) or enrich (positive consequence) defined by its environmental resources.

10) Body of development implementation - legal framework.

In order to achieve the needs were used aerial photographs of the area, orthophotographs of the area in digital form, management plan, silvicultural map of the cluster and geological map. For the field measurements were used GPS, 
compass, clinometer, and measure tape. Also we took information from the residents and the municipality for the cultural inheritance and the area was step out in order to take elements for the natural, artificial environment and the existing infrastructure works and of course for the determination of the proper, suitable places for the installation of the suggested works.

Geographical Information Systems (GIS) help in survey, evaluation and assessment of the anthropogenic impacts on the environment. The determination of the existing road density and land uses are done with the use of GIS (length of roads, topology etc.) from the digitized map of the research area on the digital orthophotography.

Especially for the compatibility control of the roads were used a series of criteria (intensity and absorbency) in order to do the evaluation of the impacts of their construction on the environment and to investigate how compatible with the environment they are or they need improvement. As the method that was used as the

For the criteria grading were used aerial photographs of the area, orthophotographs of the area in digital form, management plan, silvicultural map of the cluster and geological map. For the field measurements were used compass, clinometer, measure tape and GPS

\section{RESULTS AND DISCUSSION}

\section{A. Geographical Position, Boundaries, Extend}

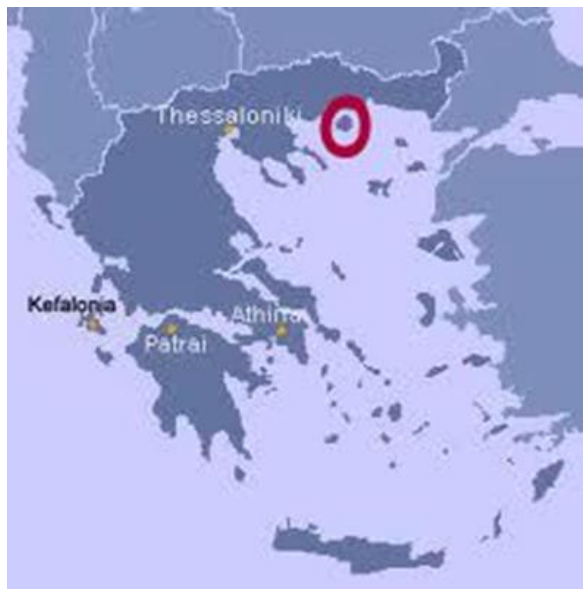

Fig. 1. Greece and Thasos Island.

The State Forest Maries-Limenaria of Thasos Island with the settlements Maries, Limenaria, Kallirachi and Sotiros, located in the south western part of the island of Thasos (Fig. 1, Fig. 2, and Fig. 3). Extends among the coordinates:

North Latitude $40^{\circ} 33^{\prime} 00^{\prime \prime}$ to $40^{\circ} 43^{\prime} 00^{\prime \prime}$ and

East Longitude $00^{\circ} 53^{\prime} 00^{\prime \prime}$ to $01^{\circ} 04^{\prime} 00^{\prime \prime}$.

The boundaries of the forest under study are as follows:

East: With public forest of Theologian.

South: Sea.

West: Sea.

North: With public forest of Prinos.

The area of forest is 4044.30 Ha broken down by type of exploitation as follows:

1) Forested area of 674.39 Ha i.e. percentage $16.67 \%$

2) Partially forested area - Scrublands of $2999.06 \mathrm{Ha}$ i.e. percentage $74.16 \%$

3) Agricultural lands of 104.64 Ha i.e. percentage $2.59 \%$

4) Bare-rangeland of $45.00 \mathrm{Ha}$ i.e. percentage $1.11 \%$

5) Arid land-Settlements of $221.21 \mathrm{Ha}$ i.e. percentage $5.47 \%$

Total 4044.30 Ha i.e. percentage $100.00 \%$.

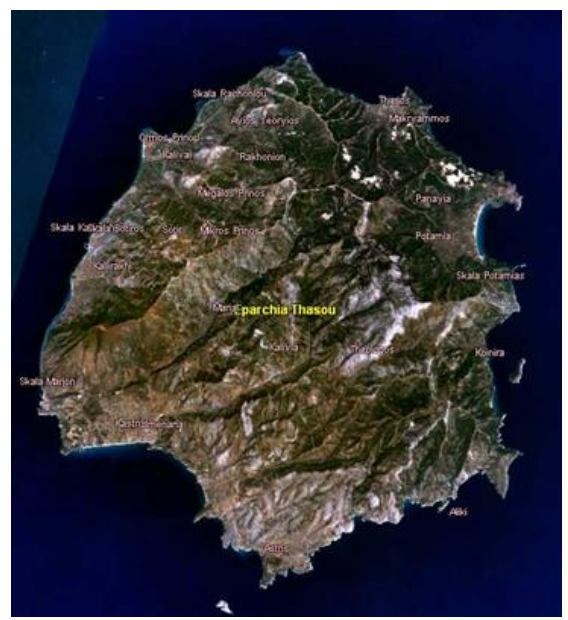

Fig. 2. The Thasos Island.

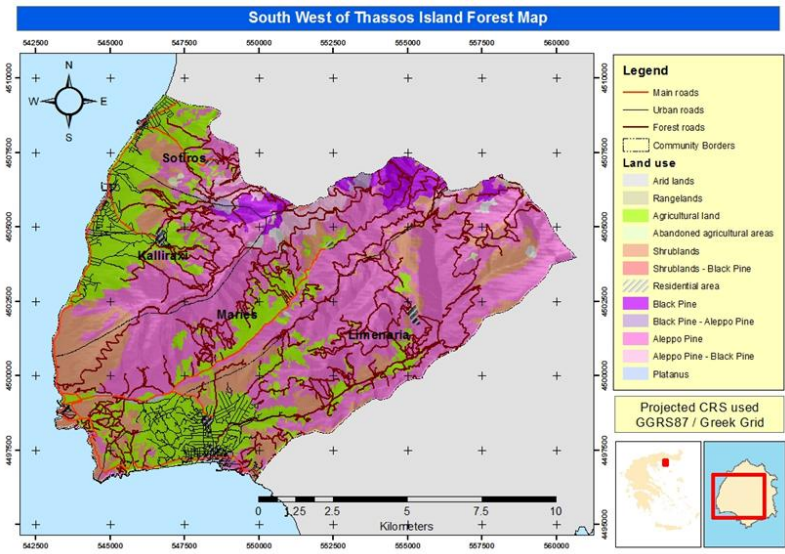

Fig. 3. The south western part of the island of Thasos.

\section{B. Description of Natural Environment}

The main streams are Maries - Lakkos and Limenarion Lakkos with direction from northeast to south-south-west (Fig. 3). Numerous of minor streams crossing in all directions in the area, creating together, main and side streams, a strong diversity in terrain. Due to the intense relief of the region with many ridges and gullies, found all the aspects. The terrain slopes are different from mild; moderate to strong and in the north-east section of the public forest are steep. The above sea level starts at $0 \mathrm{~m}$ at sea and arrives at 1,114.41 m (Fig. 4).

There are few springs with enough water. Some of these springs have been reserved for water supply of settlements.

The Island is formed mainly by gneisses, schists and marbles of the Rhodope Massif. A large low-angle thrust cuts the gneiss, schist and marble sequence at the south-west corner of the island, probably indicating an over thrusting of the Serbomacedonian Massif onto the Rhodope Massif.

The climate of the region under study is Mediterranean type and the bioclimatic nature is intense medium-Mediterranean, with a number of biologically dry days during the warm period between 75 and 100. In general, the climate can be described as not very favorable for the 
development of forest vegetation of the species in that area, with no rain falls during the germination period.

The main forestry species involved in the composition of woody capital is Pinus Brutia, Pinus Nigra (Black Pine), Oak, Plane, a few Abies Chephalonika (Fir) trees and finally, various broad-leaved evergreens as a dense undergrowth of Pinus Brutia. Pinus Brutia in this region is extremely favourable growing conditions; it is the final union KLIMAX.

In herbaceous vegetation there are: erica arborea, erica verticilata, Quercus ilex, Arbutus unedo, Phillyrea latifolia $\kappa \alpha 1$ Fraxinus ornus etc.

The fire is the only threatening and devastating threat for this forest, which is always there.

The real wood stock of Pinus Brutia (not including the undergrowth) amounts to 22,488.99 cubic meters and the Pinus Nigra real wood stock (not including the undergrowth and Plane) amounts to 76,829.56 cubic meters.

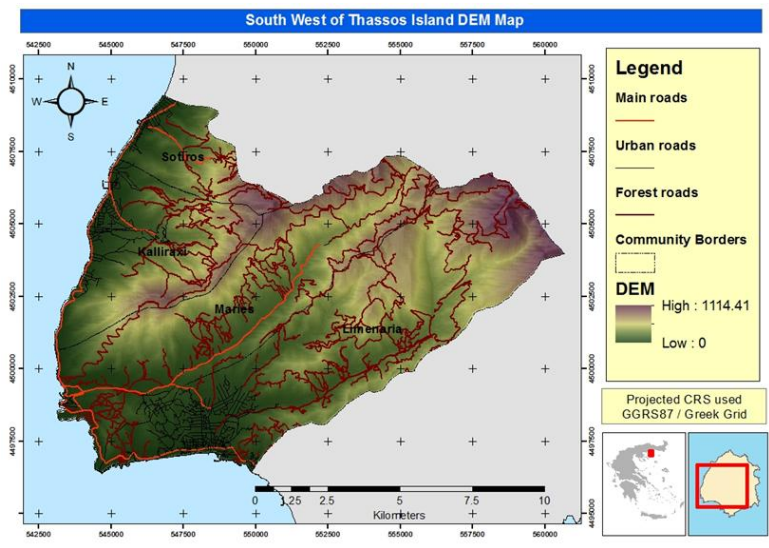

Fig. 4. The DEM map of south western Thasos Island.

\section{Description of the Human Environment}

\section{1) Ownership}

All forests in Thasos belong to Greek state and manage from this, after the liberation from the Ottoman state in 1912. In 1930 was given to the Communities of the island, area of 16,600 ha in accordance with Articles 62, 63 etc. of Law. 4173/1929.

\section{2) Population evolvement}

The population in Communities Marion, Limenaria and Theologian, amounts to 4,576 inhabitants.

Part of the population engaged in tourism, agriculture and animal husbandry with little. The people engaged primarily in mining of marbles in recent years, however that stopped or reduced the operation of the mines are employed in tourism in the region and with the beekeeping. In recent years the ecotourism is being developing, too.

\section{Description Cultural Environment}

In the cluster of Maries - Limenaria which is under study in this paper one can visit the Folk Museum of Limenaria, Palataki, and the Monastery of the Assumption of the Theotokos.

\section{E. Description of the Artificial Environment}

In the wide area of the public forest of Maries - Limenaria there are many shops selling items of tourist interest, souvenirs, restaurants, taverns, etc. employing large numbers of people.

The forest, crossed across from the provincials asphalted roads Genna - Maries and Kazaviti - Sword - Genna - Vatos. Number of forest roads from the provincial network cross over almost all sections and stands and create a quite satisfactory in terms of density forest road network in order to meet the needs of the rational management of the forest.

\section{F. Analysis of Objectives}

The aim of this study is the commensurate development of the region in all three sectors of the semi-mountain economy that forest - agriculture, livestock and tourism. Essential prerequisite for achieving this objective is the rational zoning of development projects in three sectors that may evolve dynamically and planned various activities and functions.

With the development of sustainable tourism will continue the demographic recovery of the island, to create new jobs both in tourist accommodations and commercial establishments. Alongside the development and construction of sports facilities will help in order to attract athletes and tourists and will create the necessary revenue to exploit the potential of the cluster, and the wider region.

The beekeeping is typically a secondary enjoyment, but is particularly important because the collection of honey is both an important economic resource; the other strongly influences the management of Pinus Brutia forest.

In the frame of multipurpose forestry, is the tourism development of the area in relation to the existence and functioning of the forest.

The increase in tourist traffic, especially to Kallirachi, helps the Monastery of the Assumption of the Theotokos which attracts a large number of believers who come to the worship.

The forest certainly contributes positively towards this with the beauty of the landscape and gives a factor of health and tranquillity. The place abundant in plane trees particularly along the streams has special aesthetic value, providing the possibility to transit enjoyment of nature and the forest. The panoramic view in every direction it provides is a pole of attraction for the tourists with the combination of "forest-sea".

\section{G. Proposed Works and Land Uses}

\section{1) Proposals for tourism}

- Improvement of the provisional roads Genna - Maries and Kazaviti - Sword - Genna - Vatos in the region.

- Expansion of settlements for the construction of holiday homes.

- Fitness Center and playground $5 \times 5$.

- Doubling the number of beds in hotels by 2015 .

- The development of suitable sites for relaxation and forest recreation in appropriate places along the place abundant in plane trees.

- Support the tourism with manufacturing local products.

- Publicity campaign of the unique natural landscape of the area due to advertising.

- By far the most important economic activity is tourism. An added value for growth of the culinary tourism in these areas is that their offer of farming products with particular emphasis on those made of local raw materials, organic products, protected designation of origin (PDO) 
or protected geographical indication (PGI) products. Typical examples are the famously Throuba olives and the famous pine honey in Thassos. The main agricultural products on the island are honey, almonds, olives and olive oil, as well as wine, sheep, goat herding and fishing. Other industries are lumber and mining which includes lead, zinc and marble, now abandoned, and were mined during ancient times.

\section{2) Proposals for the forests - Agriculture}

- Develop recreation areas with landscaping of sight sites the construction of open canopies in harmony with the natural environment, the construction of forest recreation areas of particular aesthetic value, by highlighting historical paths and trails for walking and hiking, and the construction of leisure parks like in Lake Genna - Small Waterfalls etc.

- Establishment of a wood workshop.

- Advertising on mountain recreation.

- The improvement of forest roads network.

We must not increase the road density, because the existing road density, Dex $=23,30 \mathrm{~m} / \mathrm{ha}$, is higher than the theoretical optimum road density, Dth $=21,57 \mathrm{~m} / \mathrm{ha}$, which has been calculated by the Kroth method. For the comparison with the Dex the Dth was used because the trucks were used as skidding means. The percentage of opening up was $86.23 \%$, which is unusually favourable.

The roads are in addition to the above requirements will serve and protect the forest from the fire.

It is necessary to maintenance each year the existing forest road network and gradually improved with widening, construction engineering, etc. to have better passable.

- Improve the management form of the forest.

- It is however necessary to make an intervention to assist and ensure adequate and progressive regeneration (Assisting the natural regeneration).

- Create a controlled hunting area and farmed game.

- Further promote biological cultivation of alternative crops to increase the income of residents.

\section{3) Proposals for stockbreeding}

- Improving the infrastructure of farming practiced by nomads in the construction of water troughs, etc.

- Subsidy for farmers practicing the combined free and housed stockbreeding and promotion through advertising of local dairy products.

\section{H. Economic Data}

\section{1) Cost of developmental projects}

1) Parking value $40000 €$.

2) Tourist accommodations worth $1500000 €$.

3) Open-shops worth $20000 €$.

4) Study of Zone of Residential Control value of $500000 €$.

5) Study of Environmental Impact Assessment or Standard Environmental Commitments value of $19000 €$. Total project development costs $2079000 €$.

\section{2) Cost of opening}

1) Maintenance cost of the opening value $73367.57 €$.

2) Recreation areas value of $150000 €$.

Total cost of opening $223367.57 €$.
General project costs $2302367.57 €$.

Can be obtained financing from the European Union to a large extent, which means it can cover the projects proposed by-Economic View.

\section{Compatibility Control with the Environment}

Controlling the compatibility of the project opening in accordance with the criteria and methodology applied has shown that the proposed improvement works to open up a whole becoming environmentally friendly. The forest roads after the improvements are compatible with the environment $59 \%, 60 \%, 68 \%$ and $51 \%$ for Category A, Category B, Category $\mathrm{C}$ and tractor roads respectively.

\section{1) For development works}

The environmental cost of the additional traffic volume is equal to the Parking, and loss of forest land will be required for the construction of holiday homes. Words:

1) Cost 1 Parking $\times 40000=40000 €$.

2) The loss of forest land by the construction of tourist accommodations: $6000 \mathrm{~m} 2 \times 35 € / \mathrm{m} 2=210000 €$.

Cost cash valued at environmental impacts (EC): $40000+$ $210000=250000 €$.

Cost of projects (CP): $2302367.57 €$.

Total cost (TC): Cost of projects (CP) + Environmental cost $(\mathrm{EC}): 2302367.57+250000=2552367.57 €$.

The depreciation of the project will be by the better organization and functioning of the tourism wandering in the forest, hill walking, archery, horseback riding, biking, rafting, hiking, the opening of outdoor shops, tourist accommodations, the operation of folklore laboratories, improving living and cultural level, etc. But all these benefits cannot be valued in money, so other valued in normal or conventional units and other quality.

The above environmental impact study, the inclusion of quantitative parameters measured in money and quality criteria for the decision of implementing the proposed projects under certain conditions regarding the protection of the natural and social environment.

\section{a) Conditions on the natural environment}

1) Seeding and mulching the places of earthworks that both the buildings and for infrastructure (sewerage, water, Parking, road network).

2) Ensure the collection and disposal of garbage from the tourist area.

3) Measures against noise.

b) Conditions related to the social environment

1) The project combines the growth character for the region with the tourist opening up of the area.

2) Trying to spread the car park for recreation and ecotourism to avoid a large burden on the environment.

3) Choose the appropriate architecture of the buildings that will be constructed so as to blend with the environment and the erection of signs at selected locations tourist importance.

4) The compulsory employment of primarily originating from the area in the construction and operation of facilities.

\section{J. Body of Development Implementation - Legal}




\section{Framework}

Because the returns on development investments are long-form and on the level of investment returns are low, these investments are more political and social character so the initial funding of the project cannot be done by private enterprise.

At the same time it is not socially acceptable these positive economic enterprises be operated by foreigners to the place of development businessmen, so should the local entity (Municipality) to determine the terms and conditions within which the private initiative is initiated.

Regarding the legal framework in accordance with Article 24 of Constitution and Articles 51, 52 of Law 998 safeguard and set the conditions for exploiting forest for tourism and sports facilities.

In this context, the private enterprise wants to switch to smaller investments as profitable hotels, restaurants, bars, rent summer sports, etc.

\section{CONCLUSION}

In summary the main benefits expected are:

- Ensuring a smooth and safe traffic of vehicles,

- Better monitoring, fire protection,

- Safe and quick transport of municipalities

- Improving the competitiveness of forest products by reducing the large costs of handling and marketing,

- Increasing tourist traffic and

- Strengthening the region's economy by increasing local employment because recruited residents of neighbouring areas to cover job.

Any development plan addresses the specific development physiognomy of the region for which drawn. Particularly for vulnerable and sensitive semi mountainous areas, integrated development is not only necessary but also feasible. A systematic mapping and monitoring land use through modern techniques in an environment of Geographic Information Systems (GIS) is necessary. The integration capabilities of modern methods and techniques and GIS to establish the necessary infrastructure integrated measurement and qualitative information on semi mountainous areas can be a very important tool for developing credible land. Necessary complement of development projects is:

1) Drafting maps land use / land cover in semi mountainous areas

2) The thematic mapping and monitoring of forests and woodlands (in terms of size, species, quality, size, health status, etc.)

3) Investigation, survey, mapping and monitoring natural and human assets and existing infrastructure in semi mountainous regions and

4) Systematic monitoring of changes in land use in semi mountainous areas.

The volume and quality measurement of the huge and qualitative information which may result from implementing such an integrated system would be valuable infrastructure making land policy in semi mountainous areas and across the Greek countryside.

Forest Cadastre and the development of the technology of computers can help in charting and assessing trends in land uses within a planned development planning.

More specifically, a framework of general strategic directions on the integrated development of semi mountainous regions especially through a specific zoning is described below:

- Complete development of semi mountainous regions (forest, stockbreeding, tourist, cultural and environmental development), elevation and utilization of the regional comparative advantages and in parallel their supplemental correlation with the broader economical-functional space of each periphery.

- Ensuring of the terms for overcoming the isolation of semi mountainous areas.

- Adjustment of the economy of the semi mountainous areas with the Communal and International process, with appropriate reformation and modernization of utilization and enterprises and the effective promotion and application of new technologies, the organizational support and motivation.

- Increase of the attractiveness of semi mountainous areas as places for obtaining relevant funds, and economical activities implementation, considering also the competitive conditions, the perspectives and proceedings in the European Union and in other countries of imminent and broader environment.

- Preservation of the landscape, the virgin forests and the forest lands, the environmental peculiarities and the cultural resources as crucial natural advantages that characterize the semi mountainous areas.

- Utilization - activation of the existing authorities of protection and development along with creation of new administrational authorities (self-government, non-governmental organizations etc.) on a corporative basis, intending the unified and integrate administration of the semi mountainous areas.

In the framework of sustainable development there are some prominent integrated zoning interventions with range of projects and activities, such as:

- Protection, rehabilitation, promotion and proper utilization of the natural heritage (national parks, landscape of special natural beauty, wetlands, fauna and flora, geomorphic formations),

- Protection, rehabilitation, promotion and proper utilization of cultural heritage (monuments of all times, anthropogenic landscapes of particular beauty, traditional settlements, vivid tradition, contemporary particular creation),

- Development of tourist alternatives to the mass concentration in the beaches, such as skiing, spa, mountainous athletic activities, ecological, cultural, agro tourist,

- Appropriate development of vegetative, stockbreeding, forest production (organic healthy products, traditional, designated products, usage of renewable sources of energy, saving water resources):

The inhabitants of the semi mountainous areas, where the appropriate conditions are available (climate, soil, relief, exposure, relevant tradition etc.) should focus on the cultivation with biological methods of vineyards for quality wines production. 
The usage of more automated methods for milking and milk collection or manufacturing of dairy products (although on a level that wouldn't harm the local and traditional features) could ensure for the inhabitants better and easier working and living conditions and furthermore favorable consequences for their social relationships.

Moreover, motives for occupation with other activities that are close to semi mountainous and forest lands should be provided, such as mushroom cultivation, forest fruits etc. Finally, an institutional definition on quality criteria (ISO) should be established in order to appeal to the market demands and ensure higher income for the occupied on this special field.

- Establishment of legislation for residence of the inhabitants also for special categories who prefer semi mountainous areas as their permanent residence, but also as a second/ vacation residence,

- Construction of infrastructure, technical and services for the population and their activities,

- Education, training, tutoring, retutoring,

- Development of initiatives with activation of the regional human factor, although offered inter locally and voluntarily (inhabitants of urban centers descending from semi mountainous areas, foreign adorers of the Greek semi-mountainous space, the Greek Diaspora),

- Institutional-administrative organization, reinforcement of spirit of coordination and corporative relationships,

- Distributional of national financial resources and providing motivations for attraction of financial resources from the broader public and private sector.

According to these developmental and spatial policies suggested the significance of zoning as the main tool for a complete and sustainable development of the semi mountainous space is becoming obvious, as well as the necessity for creating a new type of administration authorities per huge spatial unit of semi mountainous space. These authorities collaborating with peripheral councils and the local development authorities could contribute effectively on the developmental procedure of semi mountainous areas.

\section{ACKNOWLEDGMENT}

This research has been co-financed by the European Union (European Social Fund - ESF) and Greek national funds through the Operational Program "Education and Lifelong Learning" of the National Strategic Reference Framework (NSRF) - Research Funding Program: Thales. Investing in knowledge society through the European Social Fund.

\section{REFERENCES}

[1] V. C. Drosos, Forest Opening Up - Skidding and Transportation of Forest Products, Giaxoudis Publishing, Greece, Thessaloniki, 2007.

[2] G. Becker, Forest Access to the Test, Germany, BLV Publishing Ltd, AFZ, vol. 9, pp. 482-483, 1995.

[3] O. Sedlak, Forest Development and Conservation, Austria, Vienna, Forest Newspaper, vol. 104, no. 7, pp. 23-25, 1993.

[4] A.-K. Doukas and V. C. Drosos, Forest Road Construction and Natural Environment, Tziolas Publications, Thessaloniki, Greece, 2013.

[5] A.-K. Doukas and A. Akca, "Studies on the application of modern photogrammetric methods in the forest paths track alignment and the Forest Cadastral," Germany, Hamburg, Forstarchiv, pp. 71-80, 1990.

[6] P. Dale and J. M. Laughlin, Land Information Management, Oxford, U.K: Clarendon Press, 1987.

[7] V. C. Drosos, S.-A. Liampas, C. Stamatiou, and V. Giannoulas, "An environmental record and monitoring system in Greek forests," in Proc. of FORMEC'09, Prague, Czech Republic, 2009.

[8] A.-K. Doukas, Forest Constructions and Natural Environment, Thessaloniki: Giaxoudis Publishing, 2004.

[9] V. Giannoulas, "Forest opening-up with modern machinery, Technico-econmic, enviromental effects," Ph.D. Thesis, Department of Forestry and Natural Environment, Greece, Thessaloniki, 2001.

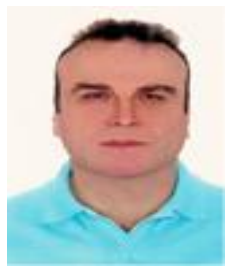

Vasileios C. Drosos was born in Katerini, Pierias Prefecture in Central Macedonia of Greece on 21st of May in 1965. He was graduated from the Department of Forestry and Natural Environment of Aristotle University of Thessaloniki in 1990. He is the holder a $\mathrm{PhD}$ title in "Forest cadastre" of the Department of Forestry and Natural Environment of Aristotle University, Thessaloniki, Greece with degree "Excellent" from 2000. His major field of study is surveying and mapping of natural environment.

$\mathrm{He}$ is an associate professor in the Department of Forestry and Management of Environment and Natural Resources in Orestiada, Greece. He published some papers.

Dr. Drosos is one member of FORMEC and PanHellenic Society of Foresters. He has above 120 publications in Greek and foreigner magazines and congresses.

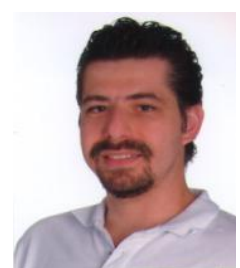

Sarantis Angelos G. Liampas was born on March 9, 1984 in Thessaloniki of Greece. He graduated from the Department of Forestry and Management of the Environment and Natural Resources of Democritus University of Thrace in Greece. He graduated in 2006. $\mathrm{He}$ also holds a master of sustainable management of the environment and natural recourses with direction in natural environment mapping and environmental impact assessment studies since 2009.

He worked three years as a forester at forest services in Northern Greece and the last three years he works as $\mathrm{PhD}$ candidate in the research funding program: Thales. His major field of study is forest opening up for timber transport and forest protection.

Mr. Liampas has above 40 publications in Greek and foreigner magazines and congresses. 